Ye Yudan

\title{
THE SCENES OF FUTURE PEACEKEEPING OPERATIONS IN THE ERA OF ARTIFICIAL INTELLIGENCE
}

\author{
DOI: $10.35926 /$ HDR.2020.1.7
}

ABSTRACT: UN led peacekeeping operations began in 1948. Since then, peacekeeping operations have gradually entered an information age that is constantly influenced and defined by computers, the Internet, etc. The invention of computer, whether or not its original intention is limited to the purpose of assisting human beings in numerical calculation, will eventually lead to the generation of intelligent machines that can extend and enhance the abilities of human beings to transform nature and govern society. When artificial intelligence is widely used and has shaped the society into a human-computer symbiotic society, peacekeeping operations must take the initiative to face the new era environment which is different from the past history of human beings, and make efforts to solve the complex problems they are facing.

KEYWORDS: peacekeeping operations, scene, era, artificial intelligence

\section{THE ERA AND ENVIRONMENT OF ARTIFICIAL INTELLIGENCE FOR PEACEKEEPING OPERATIONS}

Peacekeeping operation is a great cause reflecting international solidarity and safeguarding the common destiny of mankind. It has helped many countries falling into war to get rid of war and achieve peace. As one of the most effective and powerful tools for the United Nations to promote and maintain international peace and security, peacekeeping operations provide support for the transition from crisis or state of war to political reconciliation in war-torn areas by responding to crises and conflicts and providing basic security guarantees, as well as helping to support new and very vulnerable state institutions in their respective regions. However, the current peacekeeping operations face many challenges and suffer a lot of personnel losses. On March 28, 2018, the Secretary General of the United Nations launched the "action for peacekeeping" initiative in the Security Council, calling for "collective action to improve United Nations peacekeeping operations". ${ }^{1}$ As of July 2019, 152 countries and 4 international and regional organizations have endorsed and committed to the declaration of common commitment on United Nations peacekeeping operations. ${ }^{2}$ The in-

\footnotetext{
1 "Secretary-General's remarks to Security Council High-Level Debate on Collective Action to Improve UN Peacekeeping Operations". 28 March 2018, https://www.un.org/sg/en/content/sg/statement/2018-03-28/secretary-generals-remarks-security-council-high-level-debate, Accessed on 20 August 2019.

2 “Action for Peacekeeping". https://peacekeeping.un.org/en/action-for-peacekeeping-a4p, Accessed on $20 \mathrm{Au}-$ gust 2019.
} 
ternational community decided to make concerted efforts to promote the political settlement of conflicts, strengthen the protection provided by peacekeeping operations, improve the security and protection of peacekeepers, and improve the partnership of peacekeeping, so as to improve the ability of the United Nations to perform peacekeeping tasks and improve the effectiveness of peacekeeping operations through reform. In these efforts to reform and improve peacekeeping operations, artificial intelligence has become an indispensable background and element of the times.

2018 is considered to be the first year for intelligent development to speed up again. Artificial intelligence is different from the previous artificial tools only for physical expansion and performance improvement of human physical abilities and sensory systems, it aims to become a cognitive and reasoning machine with a certain degree of initiative; it is not only a tool used by human beings, but also a thinking assistant of human beings. Artificial intelligence is divided into software and hardware, including virtual robot and physical robot. It can imitate the human way of thinking to "think", or it can analyze and solve problems in a way different from that of humans.

Artificial intelligence came into being with the invention of computer in the 1950s. It was not developing to a higher level than the computer. It experienced a long period of low development. Until the first decade of the 21st century, due to the use of big data and the invention of machine learning algorithm, it began to develop rapidly. Especially around 2018, when the governments of many countries in the world paid more and more attention to artificial intelligence, and formulated policies and plans to lead and promote the development of artificial intelligence in their own countries, which make artificial intelligence present a global trend of cluster development and in-depth development. Artificial intelligence has been or will be widely used in many fields, such as economy, politics, society, national defense and so on. The United Nations website also publishes a special report entitled "UAVs escort humanitarian, development and peacekeeping operations". ${ }^{3}$ Artificial intelligence-based machines, including UAVs, will eventually become ubiquitous and easy after a period of development, application and supervision, just like the application of mobile phones in human society. At the present time of geopolitical disputes, we cannot ignore the changes of the times that will have a huge impact on the whole human society. In the future, how to adapt to the inevitable environment of the era of artificial intelligence and how to strengthen the research on the impact and application of artificial intelligence from now on should become the key step and content of "promoting peacekeeping with action" in the global society.

\section{THE SCENES OF FUTURE PEACEKEEPING OPERATIONS}

The era of artificial intelligence has just begun. The first 20 years of the 21 st century can only be regarded as the beginning of this long era. At present, there are some universities and research institutions in various countries, which have started the tracking research of artificial intelligence development that will last for at least 100 years. At the beginning of the 2020s, we should not only deal with the current problems of peacekeeping operations but also explore the possible evolution path of artificial intelligence, think about the possible scenes of peacekeeping operations in the long development process of artificial intelligence,

3 “Special report". https://news.un.org/zh/story/2018/05/1008052, Accessed on 20 August 2019. 
analyze the major opportunities and challenges of peacekeeping operations in such an era and background, so as to continue to determine the direction and target for the countermeasures we should take.

As a new key technology, artificial intelligence will develop in coordination with energy technology, new material technology and biotechnology in the future. However, in view of the leading role of artificial intelligence in many emerging technologies, it is necessary to analyze the development context and trend of artificial intelligence itself. As a major factor to change the future social production and lifestyle, artificial intelligence will also play a significant role in shaping the scene of future peacekeeping operations. This requires us to comprehensively consider the time dimension of the development of artificial intelligence and the space dimension of future peacekeeping scenes. In the era of artificial intelligence, peacekeeping operations will face more diverse, more complex and more dangerous scenes.

At present, the United Nations has 14 peacekeeping missions, including the United Nations Mission for Justice Support in Haiti (MINUJUSTH), the United Nations Mission for the Referendum in Western Sahara (MINURSO) and the United Nations Multidimensional Integrated Stabilization Mission in the Central African Republic (MINUSCA). ${ }^{4}$ These peacekeeping operations in conflict or crisis areas caused by various historical reasons, face different risks. In the era of artificial intelligence, peacekeepers will face not only the existing peacekeeping scenes, but also the more complex new situations caused by artificial intelligence or closely related to the development of artificial intelligence.

In the era of artificial intelligence, peacekeepers in countries or regions that already have political, religious, and ethnic conflicts will encounter a peacekeeping situation in which the original conflicts caused by artificial intelligence are getting worse.

In politics, peacekeepers will be in a more complex environment of election public opinion, and people will not be able to distinguish between true and false information related to the election by their own experience. In the first 20 years of the $21^{\text {st }}$ century, the election in many countries in the world will attach great importance to the use and supervision of Internet public opinion. The election of some political figures cannot even be won without the application of Internet tools such as Twitter. If the former network environment is mainly affected by a large number of "network water forces" employed by some countries or organizations, then in the era of artificial intelligence, the election videos and election articles on the network will be more deeply affected by the development of artificial intelligence technology.

At present, artificial intelligence technology in a natural language, image video and other fields are able to automatically generate very realistic video images of specific natural environments, backgrounds, and virtual characters, and let such virtual characters make statements or dialogues in various languages with sound and mouth pattern matching. Artificial intelligence tools can automatically analyze millions of web articles, automatically debug billions of parameters, and generate "real" articles in various languages. Only relying on human resources, it is impossible to determine which ones belong to real news videos and reports written by human beings, and which belong to "fake" news automatically generated by machines. Many of these AI video- and text-editing tools are cutting-edge technology not the only in some powerful countries. Many poor countries and non-governmental organizations can also master them. Therefore, many political elections around the world will inev-

4 “Where we operate". https://peacekeeping.un.org/en/where-we-operate, Accessed on 20 August 2019. 
itably be affected by the large-scale public opinion tools of artificial intelligence network. For some countries with deep democratic traditions and strong self-organization ability of the people, this may only cause some local electoral disturbances. However, for some other countries with serious political opposition or political estrangement, the network public opinion environment, greatly influenced and shaped by artificial intelligence, will mislead the election attitude and alter the voting direction of a large number of people, and may trigger a series of political crises and bloody conflicts. In the era of artificial intelligence, peacekeeping operations will also fall into such a complex network public opinion environment, and the credibility of peacekeeping operations will also suffer many negative effects of artificial intelligence-made fake news.

In terms of religious and ethnic conflicts, it will be impacted by the rapid development of biotechnology due to artificial intelligence. According to reports, Google's latest artificial intelligence AlphaFold program automatically analyzes the three-dimensional structure of human life basic molecules and proteins according to the gene sequence. The structure of protein affects the function of protein. Many diseases that human body will suffer from are related to the change of protein structure. If people can accurately analyze the three-dimensional structure of protein, they will be able to carry out more accurate treatment at the level of human molecular structure. Of course, just as the invention of gunpowder is not for war but may eventually be used for war, there is a great possibility that biotechnology, which is greatly promoted by artificial intelligence, will be used by some stubborn and radical scientists or terrorist organizations to transform the normal human body, thus giving birth to people with some new functions. This will shake the traditional cognition of specific religious groups about how human beings are created, which may be guided and utilized by some political factions or terrorist forces, generate new religious conflicts, and even develop into regional conflicts that need the intervention of the international community. This artificial intelligence-based biotechnology may also be possessed by some countries or terrorist organizations for the development of genetic biological weapons for specific ethnic groups. Through the covert delivery to some people in specific areas, it causes incalculable casualties and the collapse of normal social order. Such new conflicts and crises that have been changed or created by artificial intelligence need peacekeepers who do targeted research and preparation in advance.

The global climate crisis will lead to the destruction of intelligent social infrastructure in some cities and the collapse of normal social order, which will become a new scene for peacekeeping operations in the era of artificial intelligence.

In 2015, under the UN Framework Convention on Climate Change (UNFCCC), nearly 200 countries around the world adopted the Paris climate agreement, which stipulates that countries will strive to keep global warming below 2 degrees Celsius, and urges countries to make further efforts to limit warming to 1.5 degrees. The agreement entered into force in November 2016. Unfortunately, some countries withdrew from the agreement in 2017 due to domestic political needs. Around October 2018, the report issued by the Intergovernmental Panel on climate change (IPCC) showed that the global temperature had increased by $1{ }^{\circ} \mathrm{C}$ by the second half of 2018. According to this trend, by 2030, the temperature of the earth will increase by 1.5 degrees. This warming range of the climate may be a dangerous critical point, because after crossing this threshold, the sharp change of global climate will, on the one hand, cause a series of dangerous weather phenomena, such as extreme drought, forest fire, floods, strong storms, etc., leading to food shortage crisis for millions of people. On the other hand, in the 2030s or 2040s it may cause great damage to many artificial intelligence 
platforms that already widely exist in human society. The automatized and intelligent water and power supply systems that artificial-intelligence society relies on may be on the verge of paralysis, which may lead to the collapse of the normal order in intelligent cities with a population of one million to ten million. The food shortage crisis, coupled with the collapse of production, life, and traffic order on a large scale, will become a new flashpoint for some countries to fall into civil strife, and also a new scene that peacekeeping operations will have to face in the future.

Since the launch of peacekeeping operations after the Second World War, people have always believed that peacekeeping operations are mostly concentrated in underdeveloped and backward countries, which may be beneficial to summarize the history of peacekeeping operations, but very harmful to predict the future of peacekeeping operations. In terms of infrastructure in developed countries, because of the application of a lot of relatively fragile advanced technologies, accidents will also occur as a consequence of major natural disasters, leading to major disasters. In March 2011, a Richter scale 9.0 Earthquake caused two nuclear power plant reactors in Fukushima Prefecture to fail, which eventually led to a small-scale explosion and leakage of hazardous nuclear materials. Japan's nuclear reactor design had not considered the impact of extreme natural disasters, leaving a major hidden danger for nuclear leakage crisis, and the impact of the accident has not yet been fully controlled. In the same way, in the development and evolution of the era of artificial intelligence, intelligent transportation, intelligent water supply and electricity network, intelligent financial system, etc. on which human society relies for operation, will be exposed to the influence of extreme weather, and may fail to function in a large range in major natural disasters such as typhoon, earthquake, flood, etc., thus destroying the normal order operation of the intelligent society. This kind of extensive and significant climate impact will make some originally more developed countries fall into a governance crisis, or even war. Such a serious prospect in the development of intelligent society needs to be clearly recognized by peacekeepers who care for the earth, love, and peace all over the world.

Known or unknown malignant infectious diseases, with the aid of highly intelligent logistics networks, can boost the epidemic in many countries and regions in a very short time, forming a more severe and complex peacekeeping operation scene.

The wide spread of disease has a profound history. For example, the outbreak of plague in Europe in the middle of the $14^{\text {th }}$ century resulted in the death of more than 25 million Europeans between 1347 and 1353. The spread of the epidemic began in Central Asia, and spread from Central Asia to the west, to the Middle East, Mediterranean, Western Europe, and finally to northern Europe by means of commercial exchanges, religious communication, Mongolian invasion, and other ways, forming a catastrophe covering medieval Europe. The large-scale spread of fatal diseases has not disappeared in modern society but has formed an important background that peacekeeping operations cannot escape. In April 2013, the United Nations decided to send a multidimensional integrated Stabilization Mission to Mali to assist the Malian government in restoring political, economic and legal order in the country. Many countries, including China, have sent peacekeeping forces to the United Nations multidimensional integrated Stabilization Mission in Mali. The peacekeeping operation in Mali has been greatly affected by the spread of the Ebola epidemic from South and Central Africa to North Africa, that is, Mali and other countries. Within five months, Ebola killed more than 1,400 people in many African countries, and few villages and communities have survived. Ebola epidemic has become a major factor that peacekeeping forces in Mali have to consider and guard against when carrying out peacekeeping operations. 
In the process of the development of intelligent society, Ebola virus, a fatal disease known to human beings, not only continues to spread through traditional channels of transmission, but is also likely to "detonate" the epidemic rapidly with the help of large-scale UAV of intelligent logistics. Small or micro UAVs and bionic micro robots that are actively developed and used by various countries will not only have high mobility like mice and flies, but will not be subject to conventional epidemic prevention methods such as spraying insecticides, setting fire and burning, making the traditional prevention methods and tools of epidemic ineffective. Peacekeepers in an epidemic-stricken area will be seriously affected by the deadly diseases transmitted by the intelligent logistics network. In addition, just as margarine, which was encouraged in the 1950 s, was later found to contain trans fatty acids, which increased the risk of heart and brain disease, in the era of artificial intelligence, some food that was invented and produced in a hurry may cause unpredictable risks and new diseases for humans. Such new diseases, as they are not listed in the original disease database, can spread rapidly in the intelligent logistics network. Even if the peacekeepers deployed in many areas take the initiative to prevent them, they will be unable to prevent infections because of the unknown mechanism and the rapid spread of the disease. Because of the food safety crisis, the peacekeepers will also encounter a large number of potential safety hazards of non-combat personnel reduction.

The popularization of artificial intelligence technology has reduced the difficulty of research and production of some weapons of mass destruction, which may lead to a new proliferation crisis of weapons of mass destruction and create a difficult situation that peacekeeping operations have to face.

The proliferation of nuclear, biological and chemical weapons has always been a major threat to peace. Although countries all over the world have formulated the non-proliferation mechanism of weapons of mass destruction and related substances, there is no obvious boundary between military and civil purposes in the relevant research. Today, there are still considerable hidden dangers in the proliferation of nuclear, biological and chemical weapons in many war-torn areas. In October 2018, China, the United States, Russia and another seven countries joined hands. The U.S. conducted diplomatic coordination with several countries, Russia sent special devices and large-scale transport aircraft to transport nuclear materials, China provided technology and site for the safe disposal of nuclear materials, and transferred about $1 \mathrm{~kg}$ of highly enriched uranium used for experiments in a university in $\mathrm{Ni}$ geria. Finally, the fissile material was safely transported to Shijiazhuang, China, to avoid the threat of "Boko Haram" terrorists engaged in terrorist activities in many regions of Nigeria, and eliminate the possibility that these nuclear materials were stolen and made into lethal dirty bombs or high explosive bombs. This joint action of many countries working together to deal with potentially stolen nuclear devices in war-torn areas also sets a model for peacekeeping operations to deal with similar weapons or devices of mass destruction, which can provide operational reference for coming intelligent society to prevent the proliferation of weapons of mass destruction or related substances.

Whether it is harmful nuclear substances, harmful organisms, or chemicals, the research in intelligent society has lowered the threshold of research and manufacturing. Since the intelligent program developed by Google can automatically analyze the three-dimensional structure of proteins for disease treatment, it also has the potential to be used to produce biological viruses with mass destruction effect. With the emergence of technologies such as intelligent additive manufacturing and intelligent synthesis of new chemical explosives, the roadside bombs faced in peacekeeping operations in the past will also be upgraded. For 
example, adding new chemical explosives with great lethality or making dirty bombs with large destructive power through intelligent 3D printing technology will create a more difficult battlefield environment for peacekeepers. If the peacekeepers do not have the ability to warn of and resist the threat of such weapons or devices of mass destruction, the development of peacekeeping operations will be unsustainable.

\section{SUMMARY}

From the perspective of science and technology, we can have more understanding and thinking about this era, the world and the future of mankind. Although there are different opinions, artificial intelligence is undoubtedly a key opportunity and a major challenge for human beings in this century. In the longer term, artificial intelligence is even a watershed for the development of the human world. Before the large-scale emergence of artificial intelligence, only human beings as the highest-level of intelligence dominated everything in the world. Afterwards, however, humans will enjoy the glory of the highest intelligence in fewer and fewer fields. Of course, artificial intelligence will play the role of human's intelligent assistant for a long time before human studies the nature of consciousness. Such ubiquitous artificial intelligence will drive human beings to an unknown, perhaps better world.

The development of the human world is not necessarily a spiral process. There are many negative factors in the human world, which affect the overall harmony and prosperity of human society. Wars and large-scale conflicts between countries or regions are undoubtedly the worst factors affecting the long-term development of human society. Peacekeeping operations initiated and deployed by the United Nations, the most representative and credible international organization, have helped many countries in conflicts to restore order and protected tens of thousands of civilians. But in this rapidly changing era, UN peacekeeping operations are facing a series of major difficulties and losses. In order to reform peacekeeping operations, to adapt to the trend of the times, and to better cope with the growing challenges of the present and future, we need people who care about world peace to think seriously, put forward effective countermeasures, and jointly help build peacekeeping operations to meet the needs of the era of artificial intelligence.

\section{BIBLIOGRAPHY}

“Action for Peacekeeping". https://peacekeeping.un.org/en/action-for-peacekeeping-a4p

"Secretary-General's remarks to Security Council High-Level Debate on Collective Action to Improve UN Peacekeeping Operations". 28 March 2018. https://www.un.org/sg/en/content/sg/statement/2018-03-28/secretary-generals-remarks-security-council-high-level-debate

"Special report". https://news.un.org/zh/story/2018/05/1008052

"Where we operate". https://peacekeeping.un.org/en/where-we-operate 